\title{
Optimal cut-off of obesity indices to predict cardiovascular disease risk factors and metabolic syndrome among adults in Northeast China
}

\author{
Jianxing Yư ${ }^{1}$ Y Yuchun Tao ${ }^{1}$, Yuhui Tao ${ }^{2}$, Sen Yang ${ }^{1}$, Yaqin Yư ${ }^{1}$ Bo Li ${ }^{1}$ and Lina Jin ${ }^{*}$
}

\begin{abstract}
Background: CVD risk factors (hypertension, dyslipidemia and diabetes) and MetS are closely related to obesity. The selection of an optimal cut-off for various obesity indices is particularly important to predict CVD risk factors and MetS.

Methods: Sixteen thousand seven hundred sixty-six participants aged 18-79 were recruited in Jilin Province in 2012. Five obesity indices, including BMI, WC, WHR, WHtR and BAl were investigated. ROC analyses were used to evaluate the predictive ability and determine the optimal cut-off values of the obesity indices for CVD risk factors and MetS.

Results: BMI had the highest adjusted ORs, and the adjusted ORs for hypertension, dyslipidemia, diabetes and MetS were 1.19 (95\% Cl, 1.17 to 1.20$), 1.20(95 \% \mathrm{Cl}, 1.19$ to 1.22$)$, $1.12(95 \% \mathrm{Cl}, 1.10$ to 1.13$)$, and 1.40 (95\% Cl, 1.38 to 1.41), respectively. However, BMI did not always have the largest adjusted AUROC. In general, the young age group (18 44) had higher ORs and AUROCs for CVD risk factors and MetS than those of the other age groups. In addition, the optimal cut-off values for WC and WHR in males were relatively higher than those in females, whereas the BAI in males was comparatively lower than that in females.

Conclusions: The appropriate obesity index, with the corresponding optimal cut-off values, should be selected in different research studies and populations. Generally, the obesity indices and their optimal cut-off values are: $\mathrm{BMI}\left(24 \mathrm{~kg} / \mathrm{m}^{2}\right)$, WC (male: $85 \mathrm{~cm}$; female: $80 \mathrm{~cm}$ ), WHR (male: 0.88; female: 0.85), WHtR (0.50), and BAI (male: $25 \mathrm{~cm}$; female: $30 \mathrm{~cm}$ ). Moreover, $W C$ is superior to other obesity indices in predicting CVD risk factors and MetS in males, whereas, WHtR is superior to other obesity indices in predicting CVD risk factors and MetS in females.
\end{abstract}

Keywords: ROC, Optimal cut-off, Obesity indices, Cardiovascular diseases, Metabolic syndrome

\section{Background}

With economic development and the improvement of living conditions, the prevalence of obesity is increasing dramatically in China [1, 2]. A number of studies have demonstrated that obesity is associated with hypertension, dyslipidemia, diabetes and MetS [3-5], and hypertension, dyslipidemia and diabetes are considered risk factors for CVD [6, 7].

\footnotetext{
* Correspondence: jinln@jlu.edu.cn

${ }^{1}$ Epidemiology and Biostatistics, School of Public Health, Jilin University, NO.

1163 Xinmin Street, Changchun 130021, Jilin, China

Full list of author information is available at the end of the article
}

To evaluate obesity, many indices have been proposed, including BMI, WC, WHR, WHtR and BAI. Generally, $\mathrm{BMI}$ is one of the most commonly used indices for obesity, which approximates body mass using a mathematical ratio of weight and height [8]. WC is the central diagnostic index of obesity and only considers abdominal obesity [9]. WHR and WHtR are indices for evaluating fat distribution using WC compared to $\mathrm{HC}$ or height $[10,11]$. Finally, BAI is an index to measure the amount of body fat that uses HC compared to height [12]. Obviously, other indices may be used to measure obesity, but we do not consider all of them here. 
Some studies indicated that WC or WHtR might be better predictors for CVD risk factors or MetS in Korean/Chinese populations [9, 13], whereas, Mbanya et al. noted that WC was the best predictor in Cameroonians [14]. Moreover, Bergman et al. found that BAI was a better predictor for African-Americans and MexicanAmericans [12], However, Lam et al. proposed that BAI is not likely to be better than BMI and does not apply to Asians [11]. Therefore, selection of the proper obesity index for specific research and study populations was a challenge.

In our study, the predictive ability and the optimal cut-off values of five obesity indices (BMI, WC, WHR, WHtR and BAI) for CVD risk factors and MetS are comprehensively investigated. Data from 16,766 participants aged 18-79 in Jilin Province were used to evaluate the obesity indices. Jilin is in central northeast China and has an annual average temperature $4.8{ }^{\circ} \mathrm{C}$ (latitude $40^{\circ} \sim 46^{\circ}$, longitude $121^{\circ} \sim 131^{\circ}$ ) [15]. Therefore, the results can be instructive and meaningful for studies related to obesity in northeast China. WC and WHtR are superior to other obesity indices in predicting CVD risk factors and MetS in our study, with optimal cut-off values of WC and WHtR of 85 (male)/80 (female) and 0.5 , respectively.

\section{Methods}

\section{Study population}

A large-scale cross-sectional survey was implemented in Jilin Province in 2012. A total of 16,766 participants who had lived in Jilin Province for more than 6 months and were 18-79 years old were selected through multistage stratified random cluster sampling (see details in Part 1 of the Additional file 1).

\section{Data measurement}

Height, weight, WC and $\mathrm{HC}$ were measured according to a standardized protocol and techniques, with the participants wearing light clothing but no shoes. Blood pressure was measured by trained professionals using a mercury sphygmomanometer. After an overnight fast, FBG and serum lipids were measured before breakfast using a Bai Ankang fingertip blood glucose monitor (Bayer, Leverkusen, Germany) and a MODULE P800 biochemical analysis machine (Roche Co., Ltd., Shanghai, China), respectively (see details in Part 2 of the Additional file 1).

The various obesity indices were calculated as follows:

$$
\begin{aligned}
\mathrm{BMI} & =\frac{\text { weight }(\mathrm{kg})}{\text { height }^{2}(\mathrm{~m})}, \mathrm{WHR}=\frac{\mathrm{WC}(\mathrm{cm})}{\mathrm{HC}(\mathrm{cm})}, \\
\mathrm{WHtR} & =\frac{\mathrm{WC}(\mathrm{cm})}{\text { height } \left.(\mathrm{cm})_{\mathrm{c}}\right)}, \mathrm{BAI}=\frac{\mathrm{HC}(\mathrm{cm})}{\operatorname{height~}^{1.5}(\mathrm{~m})}-18
\end{aligned}
$$

\section{Assessment criteria}

CVD risk factors refer to hypertension, dyslipidemia and diabetes in our study. Hypertension was defined as resting SBP $\geq 140 \mathrm{mmHg}$ and/or DBP $\geq 90 \mathrm{mmHg}$ and/or by the use of antihypertensive medication in the past two weeks [16]. Dyslipidemia was defined as use of lipidlowering drugs or having one or more of the following: $\mathrm{TG} \geq 1.7 \mathrm{mmol} / \mathrm{L}, \mathrm{TC} \geq 5.2 \mathrm{mmol} / \mathrm{L}, \mathrm{HDL}-\mathrm{C}<1.0 \mathrm{mmol} /$ $\mathrm{L}$ and $\mathrm{LDL}-\mathrm{C} \geq 3.4 \mathrm{mmol} / \mathrm{L}$ [17]. Diabetes was defined as the use of hypoglycemic agents or a self-reported history of diabetes or FBG of $7.0 \mathrm{mmol} / \mathrm{L}$ or more [18]. MetS [19, 20] was defined as three or more of the following conditions clustered in one subject: a) $\mathrm{WC} \geq$ $85 \mathrm{~cm}$ for males or $\geq 80 \mathrm{~cm}$ for females; b) $\mathrm{TG} \geq$ $1.7 \mathrm{mmol} / \mathrm{L}$ or ongoing hypertriglyceridemia treatment; c) HDL-C $<1.00 \mathrm{mmol} / \mathrm{L}$ for males or $<1.30 \mathrm{mmol} / \mathrm{L}$ for females, or ongoing treatment; d) SBP $\geq 130 \mathrm{mmHg}$ and $\mathrm{DBP} \geq 85 \mathrm{mmHg}$, or ongoing antihypertensive drug therapy; and e) FBG $\geq 5.6 \mathrm{mmol} / \mathrm{L}$ or ongoing anti-diabetic drug treatment.

\section{Statistical analyses}

The continuous variables were expressed as the means \pm standard deviations (SD) and compared using the $t$ test. The categorical variables were expressed as counts or percentages and compared using the Rao-Scott- $x^{2}$ test. ROC analyses were used to compare the predictive ability and determine the optimal cut-off values of the various obesity indices for CVD risk factors and MetS [21]. The value that led to the maximum Youden index (SEN + SPE -1) [22] was taken as the optimal cut-off value, and the AUROC was the index of the predictive ability. Logistic regression models were used to calculate the ORs and to evaluate the obesity indices. All statistical analyses were performed using IBM SPSS 20.0. (SPSS Inc., New York, NY, USA) Statistical significance was set at a $P$ value $<0.05$.

\section{Results}

The characteristics of the participants are shown in Table 1. Females had a higher age, TC, LDL-C and HDL-C than males $(P<0.05)$, but other anthropometric indices were significantly higher in males than those in females $(P<0.01)$. The prevalence of hypertension, dyslipidemia, diabetes, and MetS differed significantly by gender and were higher in males than in females $(P<0.05)$.

For an overview of each obesity index, Table 2 presents the adjusted ORs and AUROCs (adjusted for gender and age). In general, BMI had the highest adjusted ORs for CVD risk factors and MetS, but it did not always have the largest adjusted AUROC. BMI, WC and WHtR had the optimal adjusted AUROC for hypertension, whereas WC, WHR and BMI had the largest adjusted AUROC 
Table 1 Descriptive characteristics of the participants by gender

\begin{tabular}{|c|c|c|c|c|c|}
\hline Variable & $\begin{array}{l}\text { All } \\
(n=16766)\end{array}$ & $\begin{array}{l}\text { Male } \\
(n=7697)\end{array}$ & $\begin{array}{l}\text { Female } \\
(n=9069)\end{array}$ & $t / x^{2}$ & $P$ value \\
\hline Age(years) & $47.80 \pm 13.18$ & $47.00 \pm 13.74$ & $48.47 \pm 12.66$ & -7.20 & $<0.001$ \\
\hline Height(cm) & $162.84 \pm 8.62$ & $169.23 \pm 6.59$ & $157.41 \pm 6.04$ & 120.19 & $<0.001$ \\
\hline Weight(kg) & $64.49 \pm 11.84$ & $69.80 \pm 11.91$ & $59.98 \pm 9.72$ & 57.84 & $<0.001$ \\
\hline WC(cm) & $82.39 \pm 10.52$ & $84.70 \pm 10.44$ & $80.44 \pm 10.19$ & 26.58 & $<0.001$ \\
\hline $\mathrm{HC}(\mathrm{cm})$ & $95.08 \pm 7.23$ & $95.58 \pm 7.2$ & $94.66 \pm 7.23$ & 8.23 & $<0.001$ \\
\hline $\mathrm{SBP}(\mathrm{mmHg})$ & $131.35 \pm 21.33$ & $134.46 \pm 19.75$ & $128.71 \pm 22.24$ & 17.74 & $<0.001$ \\
\hline $\mathrm{DBP}(\mathrm{mmHg})$ & $80.01 \pm 11.74$ & $82.33 \pm 11.73$ & $78.04 \pm 11.39$ & 23.89 & $<0.001$ \\
\hline $\mathrm{TC}(\mathrm{mmol} / \mathrm{L})$ & $4.90 \pm 1.08$ & $4.88 \pm 1.06$ & $4.92 \pm 1.10$ & -2.50 & 0.012 \\
\hline $\mathrm{TG}(\mathrm{mmol} / \mathrm{L})$ & $1.96 \pm 1.80$ & $2.17 \pm 2.09$ & $1.79 \pm 1.49$ & 13.51 & $<0.001$ \\
\hline LDL-C(mmol/L) & $2.94 \pm 0.89$ & $2.89 \pm 0.86$ & $2.98 \pm 0.92$ & -6.25 & $<0.001$ \\
\hline $\mathrm{HDL}-\mathrm{C}(\mathrm{mmol} / \mathrm{L})$ & $1.39 \pm 0.39$ & $1.35 \pm 0.41$ & $1.42 \pm 0.36$ & -11.89 & $<0.001$ \\
\hline FBG (mmol/L) & $5.38 \pm 1.66$ & $5.52 \pm 1.68$ & $5.27 \pm 1.64$ & 9.94 & $<0.001$ \\
\hline Hypertension & 6249(37.27 \%) & $3162(41.08 \%)$ & $3087(34.04 \%)$ & 88.31 & $<0.001$ \\
\hline Dyslipidemia & $6679(39.76 \%)$ & $3410(44.30 \%)$ & $3269(36.05 \%)$ & 118.44 & $<0.001$ \\
\hline Diabetes & 1688(10.07 \%) & $820(10.65 \%)$ & $868(9.57 \%)$ & 5.39 & 0.02 \\
\hline MetS & 5535(33.01 \%) & 2638(34.27 \%) & 2897(31.94 \%) & 10.21 & 0.001 \\
\hline
\end{tabular}

for dyslipidemia, diabetes and MetS, respectively. Moreover, BAI did not have a better adjusted OR or AUROC for any CVD risk factor or MetS in our study.

Then, the detailed performance of 5 obesity indices associated with CVD risk factors and MetS was investigated. For females (Table 3), the ORs and AUROCs of the obesity indices for CVD risk factors and MetS were the largest in the $18 \sim 44$ age group, followed by the $45 \sim 64$ group. Thus, obesity in the younger age groups was at a higher risk for CVD risk factors and MetS (higher ORs), and it had better predictive ability for CVD risk factors and MetS as well (larger AUROC). Further, the AUROC for males had a similar tendency and characteristics as that of females (see Additional file 1: Table S3).

The detailed optimal operating points (OOPs) for BMI, WC, WHR, WHtR and BAI to predict CVD risk factors and MetS are given in Table 4, in which the OOP is the cut-off value that leads to the maximum Youden index (SEN + SPE -1) [22]. Obviously, the OOPs for different risk factors were different, so we chose a single accessible value (close to the mean of the OOPs) as the optimal cut-off value for each index. For example, the OOPs of BMI for CVD risk factors and MetS ranged from 23.24 to 24.48 , so we chose 24 as the optimal cutoff value for BMI, whereas the OOPs of WC ranged from 84.13 to 85.74 for males and 79.32 to 81.58 for females, so we chose 85 and 80 as the optimal WC cut-off values. Similarly, the optimal cut-off value for WHR was 0.88 and 0.85 , for WHtR was 0.5 , and for BAI was 25 and 30, respectively. In addition, the optimal cut-off values of BMI and WHtR were the same in both genders, whereas the optimal cut-off values of WC and WHR in males were relatively higher than those in females, but the opposite occurred for BAI. Generally, most of the optimal index cut-off values were the same as or similar to other studies in literature $[10,11,13,23]$.

Table 2 Adjusted ORs and adjusted AUROC for obesity indices in relation to CVD risk factors and MetS

\begin{tabular}{|c|c|c|c|c|c|c|c|c|}
\hline & \multicolumn{2}{|l|}{ Hypertension } & \multicolumn{2}{|l|}{ Dyslipidemia } & \multicolumn{2}{|l|}{ Diabetes } & \multicolumn{2}{|l|}{ MetS } \\
\hline & $\begin{array}{l}\text { Adjusted } \\
\text { OR(95 \% Cl) }\end{array}$ & $\begin{array}{l}\text { AUROC } \\
(95 \% \mathrm{Cl})\end{array}$ & $\begin{array}{l}\text { Adjusted } \\
\text { OR(95 \% Cl) }\end{array}$ & $\begin{array}{l}\text { AUROC } \\
(95 \% \text { Cl) }\end{array}$ & $\begin{array}{l}\text { Adjusted } \\
\text { OR(95 \% Cl) }\end{array}$ & $\begin{array}{l}\text { AUROC } \\
(95 \% \mathrm{Cl})\end{array}$ & $\begin{array}{l}\text { Adjusted } \\
\text { OR(95 \% Cl) }\end{array}$ & $\begin{array}{l}\text { AUROC } \\
(95 \% \text { Cl) }\end{array}$ \\
\hline $\mathrm{BMI}$ & $1.19(1.17,1.20)$ & $0.77(0.76,0.78)$ & $1.20(1.19,1.22)$ & $0.71(0.70,0.72)$ & $1.12(1.10,1.13)$ & $0.73(0.72,0.74)$ & $1.40(1.38,1.41)$ & $0.81(0.80,0.81)$ \\
\hline WC & $1.06(1.06,1.07)$ & $0.77(0.76,0.78)$ & $1.08(1.07,1.08)$ & $0.73(0.72,0.73)$ & $1.05(1.05,1.06)$ & $0.74(0.73,0.75)$ & $1.15(1.14,1.16)$ & $0.78(0.77,0.79)$ \\
\hline WHR & $1.08(1.07,1.09)$ & $0.76(0.75,0.76)$ & $1.12(1.11,1.12)$ & $0.71(0.71,0.72)$ & $1.08(1.07,1.09)$ & $0.75(0.73,0.76)$ & $1.19(1.18,1.20)$ & $0.78(0.78,0.79)$ \\
\hline WHtR & $1 \cdot 11(1 \cdot 10,1 \cdot 11)$ & $0.77(0.76,0.78)$ & $1.13(1.12,1.14)$ & $0.72(0.71,0.73)$ & $1.09(1.08,1.10)$ & $0.74(0.73,0.75)$ & $1.25(1.24,1.26)$ & $0.79(0.78,0.80)$ \\
\hline BAl & $1.13(1.12,1.14)$ & $0.75(0.74,0.76)$ & $1.13(1.12,1.14)$ & $0.66(0.65,0.67)$ & $1.07(1.07,1.08)$ & $0.71(0.70,0.72)$ & $1.23(1.21,1.24)$ & $0.75(0.74,0.76)$ \\
\hline
\end{tabular}

The OR and AUROC were adjusted for gender and age 
Table 3 ORs and AUROCs for the obesity indices in relation to CVD risk factors and MetS in females by age group

\begin{tabular}{|c|c|c|c|c|c|c|}
\hline & \multicolumn{2}{|l|}{$18 \sim 44$} & \multicolumn{2}{|l|}{$45 \sim 64$} & \multicolumn{2}{|l|}{$65 \sim 79$} \\
\hline & $\mathrm{OR}$ & AUROC & $\mathrm{OR}$ & AUROC & $\mathrm{OR}$ & AUROC \\
\hline \multicolumn{7}{|c|}{ Hypertension } \\
\hline BMl & $1.23(1.20,1.26)$ & $0.70(0.68,0.72)$ & $1.17(1.15,1.19)$ & $0.64(0.62,0.66)$ & $1.11(1.07,1.16)$ & $0.66(0.62,0.69)$ \\
\hline WC & $1.09(1.07,1.10)$ & $0.70(0.68,0.72)$ & $1.06(1.05,1.07)$ & $0.64(0.62,0.66)$ & $1.04(1.02,1.06)$ & $0.65(0.61,0.69)$ \\
\hline WHR & $1.09(1.08,1.11)$ & $0.69(0.67,0.71)$ & $1.08(1.07,1.09)$ & $0.63(0.61,0.65)$ & $1.04(1.02,1.06)$ & $0.64(0.60,0.68)$ \\
\hline WHtR & $1.14(1.12,1.16)$ & $0.70(0.68,0.72)$ & $1.10(1.09,1.12)$ & $0.64(0.62,0.66)$ & $1.06(1.04,1.09)$ & $0.67(0.63,0.70)$ \\
\hline BAI & $1.17(1.14,1.20)$ & $0.66(0.64,0.68)$ & $1.12(1.10,1.14)$ & $0.60(0.58,0.62)$ & $1.07(1.03,1.11)$ & $0.64(0.60,0.68)$ \\
\hline \multicolumn{7}{|c|}{ Dyslipidemia } \\
\hline BMI & $1.18(1.16,1.21)$ & $0.74(0.72,0.76)$ & $1.15(1.12,1.17)$ & $0.71(0.69,0.72)$ & $1.08(1.05,1.12)$ & $0.69(0.65,0.72)$ \\
\hline WC & $1.07(1.06,1.08)$ & $0.75(0.73,0.76)$ & $1.06(1.06,1.07)$ & $0.72(0.70,0.73)$ & $1.05(1.03,1.06)$ & $0.68(0.65,0.72)$ \\
\hline WHR & $1.10(1.08,1.11)$ & $0.74(0.72,0.76)$ & $1.10(1.08,1.11)$ & $0.70(0.68,0.71)$ & $1.06(1.04,1.09)$ & $0.67(0.63,0.71)$ \\
\hline WHtR & $1.12(1.10,1.13)$ & $0.75(0.73,0.77)$ & $1.10(1.09,1.11)$ & $0.71(0.70,0.73)$ & $1.06(1.04,1.08)$ & $0.68(0.64,0.71)$ \\
\hline BAl & $1.12(1.10,1.15)$ & $0.68(0.67,0.70)$ & $1.09(1.07,1.10)$ & $0.63(0.62,0.65)$ & $1.03(1.00,1.06)$ & $0.60(0.56,0.64)$ \\
\hline \multicolumn{7}{|l|}{ Diabetes } \\
\hline BMl & $1.17(1.12,1.22)$ & $0.65(0.61,0.70)$ & $1.10(1.07,1.12)$ & $0.62(0.59,0.64)$ & $1.11(1.06,1.16)$ & $0.62(0.57,0.67)$ \\
\hline WC & $1.08(1.06,1.10)$ & $0.68(0.64,0.73)$ & $1.05(1.04,1.06)$ & $0.65(0.62,0.67)$ & $1.04(1.02,1.06)$ & $0.61(0.56,0.66)$ \\
\hline WHR & $1.10(1.07,1.14)$ & $0.70(0.66,0.74)$ & $1.10(1.08,1.11)$ & $0.65(0.63,0.67)$ & $1.03(1.01,1.06)$ & $0.60(0.54,0.65)$ \\
\hline $\mathrm{WH}$ tR & $1.13(1.10,1.17)$ & $0.69(0.65,0.74)$ & $1.08(1.07,1.10)$ & $0.64(0.61,0.66)$ & $1.07(1.04,1.10)$ & $0.61(0.56,0.66)$ \\
\hline BAl & $1.10(1.05,1.16)$ & $0.63(0.58,0.67)$ & $1.06(1.03,1.08)$ & $0.56(0.54,0.59)$ & $1.07(1.03,1.12)$ & $0.56(0.51,0.61)$ \\
\hline \multicolumn{7}{|l|}{ MetS } \\
\hline $\mathrm{BMl}$ & $1.39(1.35,1.43)$ & $0.84(0.82,0.85)$ & $1.32(1.29,1.34)$ & $0.80(0.78,0.81)$ & $1.24(1.19,1.30)$ & $0.79(0.76,0.82)$ \\
\hline WC & $1.17(1.15,1.18)$ & $0.86(0.85,0.87)$ & $1.13(1.12,1.14)$ & $0.83(0.82,0.84)$ & $1.10(1.08,1.12)$ & $0.83(0.80,0.85)$ \\
\hline WHR & $1.18(1.16,1.20)$ & $0.83(0.81,0.84)$ & $1.17(1.15,1.18)$ & $0.79(0.77,0.80)$ & $1.11(1.08,1.13)$ & $0.77(0.74,0.80)$ \\
\hline WHtR & $1.26(1.24,1.29)$ & $0.85(0.84,0.86)$ & $1.21(1.19,1.22)$ & $0.81(0.80,0.83)$ & $1.15(1.12,1.18)$ & $0.81(0.78,0.84)$ \\
\hline BAl & $1.27(1.24,1.3)$ & $0.75(0.73,0.77)$ & 1.18(1.16,1.2) & $0.69(0.68,0.71)$ & $1.11(1.07,1.15)$ & $0.69(0.65,0.73)$ \\
\hline
\end{tabular}

Table 4 Optimal operating points of the obesity indices for predicting CVD risk factors and MetS

\begin{tabular}{|c|c|c|c|c|c|c|c|c|c|c|c|c|c|c|c|}
\hline & \multicolumn{3}{|l|}{$\mathrm{BMI}$} & \multicolumn{3}{|l|}{ WC } & \multicolumn{3}{|l|}{ WHR } & \multicolumn{3}{|l|}{$\mathrm{WHtR}$} & \multicolumn{3}{|l|}{ BAl } \\
\hline & $\begin{array}{l}\mathrm{OOP} \\
\left(\mathrm{kg} / \mathrm{m}^{2}\right)\end{array}$ & $\begin{array}{l}\text { SEN } \\
(\%)\end{array}$ & $\begin{array}{l}\text { SPE } \\
(\%)\end{array}$ & $\begin{array}{l}\text { OOP } \\
(\mathrm{cm})\end{array}$ & $\begin{array}{l}\text { SEN } \\
(\%)\end{array}$ & $\begin{array}{l}\text { SPE } \\
(\%)\end{array}$ & OOP & $\begin{array}{l}\text { SEN } \\
(\%)\end{array}$ & $\begin{array}{l}\text { SPE } \\
(\%)\end{array}$ & $\begin{array}{l}\text { OOP } \\
(\mathrm{cm} / \mathrm{kg})\end{array}$ & $\begin{array}{l}\text { SEN } \\
(\%)\end{array}$ & $\begin{array}{l}\text { SPE } \\
(\%)\end{array}$ & OOP & $\begin{array}{l}\text { SEN } \\
(\%)\end{array}$ & $\begin{array}{l}\text { SPE } \\
(\%)\end{array}$ \\
\hline \multicolumn{16}{|l|}{ Male } \\
\hline Hypertension & 23.24 & 73.41 & 49.03 & 84.56 & 67.13 & 57.21 & 0.88 & 71.78 & 54.14 & 0.48 & 76.11 & 51.11 & 24.74 & 70.12 & 51.13 \\
\hline Dyslipidemia & 23.81 & 72.29 & 61.01 & 84.13 & 70.19 & 64.64 & 0.88 & 72.32 & 59.87 & 0.49 & 74.04 & 60.62 & 24.83 & 69.14 & 53.18 \\
\hline Diabetes & 24.46 & 63.72 & 56.18 & 85.74 & 69.13 & 56.32 & 0.89 & 71.14 & 57.43 & 0.50 & 74.28 & 51.21 & 25.11 & 67.79 & 47.81 \\
\hline MetS & 24.48 & 78.10 & 70.47 & 84.92 & 88.62 & 70.71 & 0.88 & 82.31 & 64.76 & 0.51 & 80.54 & 72.04 & 25.10 & 74.63 & 58.42 \\
\hline \multicolumn{16}{|l|}{ Female } \\
\hline Hypertension & 23.64 & 71.33 & 56.39 & 80.14 & 71.71 & 63.12 & 0.85 & 71.13 & 60.55 & 0.51 & 71.42 & 65.36 & 29.44 & 71.12 & 56.23 \\
\hline Dyslipidemia & 23.25 & 75.17 & 51.12 & 79.32 & 72.62 & 58.81 & 0.84 & 72.22 & 57.68 & 0.50 & 73.83 & 58.87 & 29.12 & 69.73 & 51.22 \\
\hline Diabetes & 24.47 & 63.42 & 58.17 & 81.58 & 71.88 & 58.59 & 0.86 & 74.83 & 61.42 & 0.52 & 77.34 & 56.69 & 30.35 & 59.14 & 58.54 \\
\hline MetS & 24.16 & 77.13 & 66.76 & 79.86 & 90.47 & 66.47 & 0.85 & 79.54 & 65.83 & 0.51 & 84.39 & 68.03 & 29.29 & 77.82 & 55.63 \\
\hline
\end{tabular}


Finally, we investigated the adjusted ORs and AUROC of each obesity index for CVD risk factors and MetS (Table 5) using the optimal cut-off values determined above. In general, the WC and WHtR had higher adjusted ORs and AUROCs for CVD risk factors and MetS, regardless of the small difference between genders. WC was superior to other obesity indices in predicting CVD risk factors and MetS in males, but WHtR was superior to other obesity indices in predicting CVD risk factors and MetS in females. Abnormal WC or WHtR was at a higher risk for CVD risk factors and MetS, whereas WC and WHtR were superior to other indices in predicting CVD risk factors and MetS.

\section{Discussion}

The prevalence of hypertension, dyslipidemia, diabetes and MetS in our study were $37.27 \%, 39.76 \%, 10.07 \%$ and $33.1 \%$, respectively, much higher than those in other studies [17]. It was believed that obesity was associated with CVD risk factors and MetS [3] and various obesity indices were used in literature $[24,25]$ to describe obesity. Unfortunately, no obesity index was consistently superior in predicting CVD risk factors and MetS, and the selection of an obesity index depended on the study population and other factors [11]. Thus, in this study, we investigated the proper obesity index and optimal cut-off values to predict CVD risk factors and MetS for a population in northeast China.

In this study, obesity in younger age groups was a higher risk and had better predictive ability for CVD risk factors and MetS than in older groups. It was implied that obesity might have more influence on young people. One possible reason was that the young people took part in fewer outdoor activities and had worse eating habits than the older people. Another possible reason was that other factors might have larger effects on CVD risk factors and MetS than obesity among older people. It was suggested that the younger the participant, the more effective it is to control obesity.

We investigated the performance of five obesity indices (BMI, WC, WHR, WHtR and BAI) for CVD risk factors and MetS in northeast China. A series of optimal cut-off values of each obesity index was determined in our study, which could provide an instructive suggestion in similar studies and populations. In summary, BMI, WC and WHtR had the same optimal cut-offs as other studies in China [13, 23], while the optimal cut-off value of WHR was a little higher [13], and that of BAI was a little lower than previous studies [12]. A probable reason might be the characteristics of Asians (especially Asian women), with smaller $\mathrm{HC}$ than Americans [26]. The higher tolerance of WHR for CVD risk factors and MetS might be due to the flexibility of fat for those in northeast China under the long duration of cold weather.

Further, WC and WHtR were superior to other obesity indices in our study, which was consistent with other studies [27-32]. Moreover, the global cut-off value of WHtR was 0.5 , which implied that this criterion might be applied to people in northeast China [10]. Meanwhile, a number of meta-analyses on CVD risk factors outcomes suggested that 0.5 (WHtR) could be appropriate for different genders and age groups [24, 33]. Moreover, the WGOC (Working Group on Obesity in China) developed a cut-off value for central obesity $(85.0 \mathrm{~cm}$ for male and $80.0 \mathrm{~cm}$ for female) using WC and overweight status $\left(24 \mathrm{~kg} / \mathrm{m}^{2}\right)$ using BMI for the general Chinese

Table 5 Adjusted ORs and AUROCs of the obesity indices associated with CVD risk factors and MetS

\begin{tabular}{|c|c|c|c|c|c|c|c|c|}
\hline & \multicolumn{2}{|l|}{ Hypertension } & \multicolumn{2}{|l|}{ Dyslipidemia } & \multicolumn{2}{|l|}{ Diabetes } & \multicolumn{2}{|l|}{ MetS } \\
\hline & $\begin{array}{l}\text { Adjusted OR } \\
(95 \% \mathrm{Cl})\end{array}$ & $\begin{array}{l}\text { AUROC } \\
(95 \% \mathrm{Cl})\end{array}$ & $\begin{array}{l}\text { Adjusted OR } \\
(95 \% \mathrm{Cl})\end{array}$ & $\begin{array}{l}\text { AUROC } \\
(95 \% \mathrm{Cl})\end{array}$ & $\begin{array}{l}\text { Adjusted OR } \\
(95 \% \mathrm{Cl})\end{array}$ & $\begin{array}{l}\text { AUROC } \\
(95 \% \mathrm{Cl})\end{array}$ & $\begin{array}{l}\text { Adjusted OR } \\
(95 \% \mathrm{Cl})\end{array}$ & $\begin{array}{l}\text { AUROC } \\
(95 \% \mathrm{Cl})\end{array}$ \\
\hline \multicolumn{9}{|l|}{ Male } \\
\hline$A 1$ & $2.62(2.37,2.89)$ & $0.61(0.59,0.62)$ & $3.97(3.61,4.37)$ & $0.65(0.65,0.67)$ & $2.34(1.99,2.74)$ & $0.60(0.58,0.61)$ & $8.93(7.94,10.04)$ & $0.74(0.73,0.75)$ \\
\hline$A 2$ & $2.65(2.40,2.93)$ & $0.62(0.61,0.63)$ & $4.21(3.82,4.63)$ & $0.67(0.66,0.68)$ & $2.81(2.36,3.35)$ & $0.63(0.61,0.65)$ & $15.81(13.94,17.92)$ & $0.79(0.78,0.80)$ \\
\hline A3 & $2.47(2.23,2.73)$ & $0.63(0.62,0.64)$ & $4.05(3.66,4.47)$ & $0.66(0.65,0.67)$ & $2.75(2.34,3.22)$ & $0.63(0.62,0.65)$ & $8.78(7.77,9.92)$ & $0.73(0.72,0.74)$ \\
\hline A4 & $2.70(2.45,2.99)$ & $0.64(0.62,0.65)$ & $4.14(3.75,4.56)$ & $0.67(0.66,0.68)$ & $2.58(2.19,3.04)$ & $0.63(0.61,0.65)$ & $11.36(10.06,12.84)$ & $0.76(0.75,0.77)$ \\
\hline A5 & $2.14(1.94,2.36)$ & $0.61(0.59,0.62)$ & $2.59(2.36,2.85)$ & $0.62(0.60,0.63)$ & $1.64(1.40,1.92)$ & $0.57(0.56,0.59)$ & $3.94(3.54,4.38)$ & $0.66(0.65,0.67)$ \\
\hline \multicolumn{9}{|c|}{ Female } \\
\hline$A 1$ & $2.60(2.35,2.87)$ & $0.64(0.62,0.65)$ & $2.44(2.22,2.67)$ & $0.63(0.62,0.64)$ & $1.98(1.70,2.30)$ & $0.61(0.59,0.63)$ & $6.32(5.68,7.04)$ & $0.72(0.71,0.70)$ \\
\hline$A 2$ & $2.86(2.58,3.17)$ & $0.68(0.66,0.69)$ & $2.71(2.46,2.98)$ & $0.66(0.64,0.67)$ & $2.53(2.13,2.99)$ & $0.65(0.63,0.67)$ & $11.53(10.20,13.03)$ & $0.78(0.77,0.79)$ \\
\hline A3 & $2.11(1.90,2.33)$ & $0.66(0.65,0.67)$ & $2.36(2.14,2.60)$ & $0.65(0.64,0.66)$ & $2.97(2.48,3.55)$ & $0.67(0.65,0.69)$ & $5.45(4.89,6.08)$ & $0.72(0.71,0.74)$ \\
\hline A4 & $2.82(2.53,3.14)$ & $0.68(0.67,0.69)$ & $2.83(2.56,3.14)$ & $0.66(0.65,0.67)$ & $2.99(2.46,3.63)$ & $0.67(0.65,0.68)$ & $10.75(9.40,12.30)$ & $0.76(0.75,0.77)$ \\
\hline A5 & $2.00(1.81,2.20)$ & $0.63(0.62,0.64)$ & $1.68(1.53,1.85)$ & $0.60(0.59,0.61)$ & $1.28(1.10,1.48)$ & $0.58(0.56,0.60)$ & $3.06(2.77,3.38)$ & $0.67(0.65,0.68)$ \\
\hline
\end{tabular}

$A 1: \mathrm{BMl}>24$ vs. $\leq 24 \mathrm{~kg} / \mathrm{m}^{2}, A 2: \mathrm{WC}>85$ vs. $\leq 85$ (men) or WC $>80$ vs. $\leq 80$ (women), $A 3: \mathrm{WHR}>0.88$ vs. $\leq 0.88$ (men) or WHR $>0.85$ vs. $\leq 0.85$ (women), $A 4:$ WHtR $>0.5$ vs. $\leq 0.5, A 5$ : $\mathrm{BAl}>25$ vs. $\leq 25$ (men) or BAl $>30$ vs. $\leq 30$ (women). The OR and AUROC were adjusted for age 
population [34], which were coincident with those in our study. In addition, other studies in Asian countries reported cut-off values of WC for males and females of approximately $80-85$ and $75-80$, respectively [35, 36], that were similar to those in our study.

Here, we indicate the limitations of our study. First, the definition of MetS overlapped with that of WC, so the AUROC and adjusted ORs for MetS might be overestimated. Despite this, the optimal WC cut-off value was consistent with the definition of MetS, which could be viewed as evidence of the rationality of our study. Second, gender and age were adjusted for in our study; however, other confounders that might have impacts on CVD risk factors and MetS, such as physical activity, smoking, etc., were not under our consideration this time, which might have some slight effect on our results.

Finally, we investigated the adjusted ORs of each index, based on the proposed optimal cut-off values. Generally, WC and WHtR were superior to other indices (larger AUROC), and the people with abnormal WC or WHtR were at higher risk (higher ORs) for CVD risk factors and MetS. Obviously, both indices could measure central obesity to some extent. Thus, it might be implied that the distribution of fat was more important than the amount of fat in predicting the risk for CVD risk factors and MetS.

\section{Conclusions}

The proper obesity index should be selected in different research studies and populations, with the corresponding optimal cut-off values. Generally, the obesity indices considered in our study and their optimal cut-off values are: BMI $\left(24 \mathrm{~kg} / \mathrm{m}^{2}\right)$, WC (male: $85 \mathrm{~cm}$; female: $80 \mathrm{~cm}$ ), WHR (male: 0.88; female: 0.85), WHtR (0.50), and BAI (male: $25 \mathrm{~cm}$; female: $30 \mathrm{~cm}$ ). Moreover, WC is superior to other obesity indices in predicting CVD risk factors and MetS in males, but WHtR is superior to other obesity indices in predicting CVD risk factors and MetS in females.

\section{Additional file}

Additional file 1: The supplementary material of the article. (DOCX $20 \mathrm{~kb})$

\footnotetext{
Abbreviations Obesity indices

BAl: Body adiposity index; BMI: Body mass index; WC: Waist circumference; WHR: Waist-hip ratio; WHtR: Waist-to-height ratio

Laboratory biochemical indicators

DBP: Diastolic blood pressure; FBG: Fasting blood glucose; HDL-C: Highdensity lipoprotein cholesterol; LDL-C: Low-density lipoprotein cholesterol; SBP: Systolic blood pressure; TC: Total cholesterol; TG: Triglyceride Other indicators

AUROC: Area under ROC; CVD: Cardiovascular disease; HC: Hip circumference; MetS: Metabolic syndrome; OR: Odds ratio; ROC: Receiver operating characteristic; SEN: Sensitivity; SPE: Specificity
}

\section{Funding}

The study was funded by the National Natural Science Foundation of China (grant number: 11301213, 11571068) and the Scientific Research Foundation of the Health Bureau of Jilin Province, China (grant number: 2011Z116).

\section{Availability of data and materials}

The survey was implemented by the School of Public Health, Jilin University and the Jilin Center for Disease Control and Prevention in Jilin Province in 2012. According to relevant regulations, we are sorry that the data cannot be shared.

\section{Authors' contributions \\ $J Y$ and $L J$ made substantial contributions to conception and design of this study. JY and $Y T$ drafted the manuscript. BL and $Y Y$ revised the manuscript. YT and SY made contribution to acquisition and performed the statistical analysis. All authors read and approved the final manuscript.}

\section{Competing interests}

The authors declare that they have no competing interests.

\section{Consent for publication}

Not applicable.

\section{Ethics approval and consent to participate}

The ethics committee of the School of Public Health, Jilin University approved the study, and written informed consent was obtained from all of the participants before data collection.

\section{Author details}

${ }^{1}$ Epidemiology and Biostatistics, School of Public Health, Jilin University, NO. 1163 Xinmin Street, Changchun 130021, Jilin, China. ${ }^{2}$ Department of Immunization Program, Changchun Center for Disease Control and Prevention, Changchun 130021, Jilin, China.

Received: 1 April 2016 Accepted: 22 September 2016

Published online: 13 October 2016

\section{References}

1. Wang Z, Hao G, Wang X, Chen Z, Zhang L, Guo M, Tian Y, Shao L, Zhu M. Current prevalence rates of overweight, obesity, central obesity, and related cardiovascular risk factors that clustered among middle-aged population of China. Zhonghua Liu Xing Bing Xue Za Zhi. 2014;35(4):354-8.

2. Andegiorgish AK, Wang J, Zhang X, Liu X, Zhu H. Prevalence of overweight, obesity, and associated risk factors among school children and adolescents in Tianjin, China. Eur J Pediatr. 2012;171(4):697-703.

3. Dankel SJ, Loenneke JP, Loprinzi PD. The impact of overweight/obesity duration on the association between physical activity and cardiovascular disease risk: an application of the "fat but fit" paradigm. Int J Cardiol. 2015;201:88-9.

4. Roberts VHJ, Frias AE, Grove KL. Impact of Maternal Obesity on Fetal Programming of Cardiovascular Disease. Physiology. 2015;30(3):224-31.

5. Lee SY, Chang HJ, Sung J, Kim KJ, Shin S, Cho IJ, Shim CY, Hong GR, Chung $\mathrm{N}$. The Impact of Obesity on Subclinical Coronary Atherosclerosis According to the Risk of Cardiovascular Disease. Obesity. 2014;22(7):1762-8.

6. Yu DH, Huang JF, Hu DS, Chen JC, Cao J, Li JX, Gu DF. Association Between Prehypertension and Clustering of Cardiovascular Disease Risk Factors Among Chinese Adults. J Cardiovasc Pharm. 2009;53(5):388-400.

7. Murakami Y, Okamura T, Nakamura K, Miura K, Ueshima H: The clustering of cardiovascular disease risk factors and their impacts on annual medical expenditure in Japan: community-based cost analysis using Gamma regression models. BMJ Open. 2013;3(3). doi:10.1136/bmjopen-2012-002234

8. Bennasar-Veny M, Lopez-Gonzalez AA, Tauler P, Cespedes ML, VicenteHerrero T, Yanez A, Tomas-Salva M, Aguilo A. Body Adiposity Index and Cardiovascular Health Risk Factors in Caucasians: A Comparison with the Body Mass Index and Others. Plos One. 2013;8(5):e63999.

9. Park SH, Choi SJ, Lee KS, Park HY. Waist Circumference and Waist-to-Height Ratio as Predictors of Cardiovascular Disease Risk in Korean Adults. Circ J. 2009;73(9):1643-50.

10. Browning LM, Hsieh SD, Ashwell M. A systematic review of waist-to-height ratio as a screening tool for the prediction of cardiovascular disease and diabetes: 0.5 could be a suitable global boundary value. Nutr Res Rev. 2010; 23(2):247-69. 
11. Lam BCC, Koh GCH, Chen C, Wong MTK, Fallows SJ. Comparison of Body Mass Index (BMI), Body Adiposity Index (BAl), Waist Circumference (WC), Waist-To-Hip Ratio (WHR) and Waist-To-Height Ratio (WHtR) as Predictors of Cardiovascular Disease Risk Factors in an Adult Population in Singapore. Plos One. 2015;10(4):e0122985.

12. Bergman RN, Stefanovski D, Buchanan $T A$, Sumner $A E$, Reynolds JC, Sebring NG, Xiang AH, Watanabe RM. A Better Index of Body Adiposity. Obesity. 2011;19(5):1083-9.

13. Zeng $Q$, He Y, Dong SY, Zhao XL, Chen ZH, Song ZY, Chang G, Yang F, Wang YJ. Optimal cut-off values of BMI, waist circumference and waist: height ratio for defining obesity in Chinese adults. Brit J Nutr. 2014;112(10): 1735-44.

14. Mbanya VN, Kengne AP, Mbanya JC, Akhtar H. Body mass index, waist circumference, hip circumference, waist-hip-ratio and waist-height-ratio: Which is the better discriminator of prevalent screen-detected diabetes in a Cameroonian population? Diabetes Res Clin Pr. 2015;108(1):23-30.

15. Gao B, Xu QT, Li YB. Dynamic Change and Analysis of Driving Factors of Carbon Emissions from Traffic and Transportation Energy Consumption in Jilin Province. Appl Mech Mater. 2014;472:851-5.

16. Yip GWK, Li AM, So HK, Choi KC, Leung LCK, Fong NC, Lee KW, Li SPS, Wong SN, Sung RYT. Oscillometric 24-h ambulatory blood pressure reference values in Hong Kong Chinese children and adolescents. J Hypertens. 2014;32(3):606-19.

17. Gu DF, Gupta A, Muntner P, Hu SS, Duan XF, Chen JC, Reynolds RF, Whelton PK, He J. Prevalence of cardiovascular disease risk factor clustering among the adult population of china - Results from the International Collaborative Study of Cardiovascular Disease in Asia (InterAsia). Circulation. 2005;112(5): 658-65.

18. Gao BX, Zhang LX, Wang HY. D CNSCK: Clustering of Major Cardiovascular Risk Factors and the Association with Unhealthy Lifestyles in the Chinese Adult Population. Plos One. 2013;8(6):e66780.

19. Wu YH, Yu Q, Wang SB, Shi JP, Xu ZQ, Zhang QQ, Fu YL, Qi Y, Liu JW, Fu R, et al. Zinc Finger Protein 259 (ZNF259) Polymorphisms are Associated with the Risk of Metabolic Syndrome in a Han Chinese Population. Clin Lab. 2015;61(5-6):615-21.

20. Alberti KG, Eckel RH, Grundy SM, Zimmet PZ, Cleeman II, Donato KA, Fruchart JC, James WP, Loria CM, Smith Jr SC. Harmonizing the metabolic syndrome: a joint interim statement of the International Diabetes Federation Task Force on Epidemiology and Prevention; National Heart, Lung, and Blood Institute; American Heart Association; World Heart Federation; International Atherosclerosis Society; and International Association for the Study of Obesity. Circulation. 2009;120(16):1640-5.

21. Dong $X L$, Liu Y, Yang J, Sun Y, Chen L. Efficiency of anthropometric indicators of obesity for identifying cardiovascular risk factors in a Chinese population. Postgrad Med J. 2011:87(1026):251-6.

22. Chen FY, Xue YQ, Tan MT, Chen PY. Efficient statistical tests to compare Youden index: accounting for contingency correlation. Stat Med. 2015;34(9): 1560-76.

23. Cai L, Liu AP, Zhang YM, Wang PY. Waist-to-Height Ratio and Cardiovascular Risk Factors among Chinese Adults in Beijing. Plos One. 2013;8(7):e69298.

24. Ashwell M, Gunn P, Gibson S. Waist-to-height ratio is a better screening tool than waist circumference and BMI for adult cardiometabolic risk factors: systematic review and meta-analysis. Obes Rev. 2012;13(3):275-86.

25. Hsieh SD, Muto T. The superiority of waist-to-height ratio as an anthropometric index to evaluate clustering of coronary risk factors among non-obese men and women. Prev Med. 2005;40(2):216-20.

26. Li CY, Ford ES, Zhao GX, Kahn HS, Mokdad AH. Waist-to-thigh ratio and diabetes among US adults: The Third National Health and Nutrition Examination Survey. Diabetes Res Clin Pr. 2010;89(1):79-87.

27. Hsieh SD, Yoshinaga H, Muto T. Waist-to-height ratio, a simple and practical index for assessing central fat distribution and metabolic risk in Japanese men and women. Int J Obesity. 2003;27(5):610-6

28. Ashwell M, Gibson S. Waist to Height Ratio Is a Simple and Effective Obesity Screening Tool for Cardiovascular Risk Factors: Analysis of Data from the British National Diet and Nutrition Survey of Adults Aged 19-64 Years. Obes Facts. 2009;2(2):97-103.

29. Tseng $\mathrm{CH}$, Chong $\mathrm{CK}$, Chan $\Pi$, Bai $\mathrm{CH}$, You SL, Chiou HY, Su TC, Chen CJ. Optimal anthropometric factor cutoffs for hyperglycemia, hypertension and dyslipidemia for the Taiwanese population. Atherosclerosis. 2010;210(2):585-9.
30. Ho SY, Lam TH, Janus ED, Fact HKCR. Waist to stature ratio is more strongly associated with cardiovascular risk factors than other simple anthropometric indices. Ann Epidemiol. 2003;13(10):683-91.

31. Haun DR, Pitanga FJG, Lessa I. Waist-Height Ratio Compared to Other Indicators of Obesity as Predictosr of High Coronary Risk. Rev Assoc Med Bras. 2009:55(6):705-11.

32. Hadaegh F, Zabetian A, Harati H, Azizi F. Waist/height ratio as a better predictor of type 2 diabetes compared to body mass index in tehranian adult men - A 3.6-year prospective study. Exp Clin Endocr Diab. 2006;114(6): $310-5$.

33. Lee CMY, Huxley RR, Wildman RP, Woodward M. Indices of abdominal obesity are better discriminators of cardiovascular risk factors than BMI: a meta-analysis. J Clin Epidemiol. 2008;61(7):646-53.

34. Zhou BF. Predictive values of body mass index and waist circumference for risk factors of certain related diseases in Chinese adults-study on optimal cut-off points of body mass index and waist circumference in Chinese adults. Biomed Environ Sci. 2002;15(1):83-96.

35. Pua $\mathrm{YH}$, Ong PH. Anthropometric indices as screening tools for cardiovascular risk factors in Singaporean women. Asia Pac J Clin Nutr. 2005; 14(1):74-9.

36. Ito H, Nakasuga K, Ohshima A, Maruyama T, Kaji Y, Harada M, Fukunaga M, Jingu S, Sakamoto $M$. Detection of cardiovascular risk factors by indices of obesity obtained from anthropometry and dual-energy X-ray absorptiometry in Japanese individuals. Int J Obesity. 2003;27(2):232-7.

\section{Submit your next manuscript to BioMed Central and we will help you at every step:}

- We accept pre-submission inquiries

- Our selector tool helps you to find the most relevant journal

- We provide round the clock customer support

- Convenient online submission

- Thorough peer review

- Inclusion in PubMed and all major indexing services

- Maximum visibility for your research

Submit your manuscript at www.biomedcentral.com/submit

) Biomed Central 